\title{
Indigenous and Scientific Kinds
}

\section{David Ludwig}

Penultimate Draft - Final version forthcoming in The British Journal for the Philosophy of Science

Abstract: The aim of this article is to discuss the relation between indigenous and scientific kinds on the basis of contemporary ethnobiological research. I argue that ethnobiological accounts of taxonomic convergence-divergence patters challenge common philosophical models of the relation between folk concepts and natural kinds. Furthermore, I outline a positive model of taxonomic convergence-divergence patterns that is based on Slater's [2014] notion of "stable property clusters” and Franklin-Hall's [2014] discussion of natural kinds as “categorical bottlenecks.” Finally, I argue that this model is not only helpful for understanding the relation between indigenous and scientific kinds but also makes substantial contributions to contemporary debates about natural kinds.

While philosophical debates about natural kinds often involve folk-biological examples such as "tiger" or "fish" (e.g. van Brakel [1992]; Dupré [1999]; Soams [2004]; Khalidi [2013]), there is a surprising lack of philosophical engagement with ethnobiological research on folk-biological taxonomies (Berlin [1992]; Ellen [2006]; Hunn and Brown [2011]). Instead, philosophers usually restrict themselves to conceptual analysis of folk-biological terms in ordinary English and do not even take notice of the vast empirical research literature on the complex biological knowledge of indigenous societies. The aim of this article is to introduce this literature to current debates about natural kinds and to develop a general model of the relation between indigenous and scientific kinds.

Sections 1-3 discuss three models of the relation between indigenous and scientific kinds that are implicit in the current literature on natural kinds. (1) Universalist realism assumes that indigenous and scientific taxa refer to the same natural kinds. (2) Revisionism argues that indigenous taxa diverge from scientific taxa because they fail to refer to natural kinds. (3) Conventionalism suggests that divergence of indigenous and scientific taxonomies undermines the very idea of natural kinds and illustrates the conventional character of biological classifications. I argue that none of these models provide a satisfying interpretation of the ethnobiological evidence about taxonomic convergence-divergence patterns. In section 4, I present Slater's [2014] account of "stable property clusters” (SPCs) as the starting point for a more comprehensive model. Slater argues that SPCs exhibit a "cliquish stability" that allow probabilistic inferences from the presence of some subclusters to the presence of others. I suggest that this cliquishness of SPCs can explain convergence of indigenous and scientific taxa but also leaves room for various forms of taxonomic divergence. Section 5 suggests that an adequate model of convergence-divergence patterns requires an extension of this model through a concept of domain-transcending SPCs and "categorical bottlenecks" in the 
sense of Franklin-Hall [2014]. Section 6 evaluates the relevance of these findings for contemporary debates about natural kinds.

\section{Universalist Realism}

Although there is a striking lack of philosophical engagement with ethnobiological research, universalist realism can be motivated by philosophical debates about the relation between folk concepts and natural kinds in the tradition of Kripke and Putnam. The common picture of a "Kripke-Putnam view” of natural kinds is not without problems (cf. Hacking [2007a]; Williams [2011]; Wikforss [2013]) but I will ignore these difficulties and only focus on the core idea that natural kind terms, like names, are rigid designators. The idea of rigid designation is usually applied to folk categories such as "gold”, “water”, or "tiger” and can support a realist interpretation of indigenous taxa even in the light of substantial differences between indigenous and scientific beliefs about biological kinds. For example, a folk-biologist may successfully refer to a natural kind such as tiger even if she has very limited knowledge or even seriously flawed beliefs about tigers. In analogy, consider names as rigid designators: I can successfully refer to Shakespeare, even if I have very limited knowledge or even seriously flawed beliefs about Shakespeare.

If we turn from philosophy to ethnobiology, it is attractive to combine the idea of rigid designators with the "intellectualist” tradition in ethnobiology (Berlin [1992]; cf. Hunn [2007] for the historical context) that postulates a universal framework of folk-biological taxonomies. According to Berlin et al. [1973], folk-taxonomies are based on a hierarchical system of ranks that defines sets and subsets. All natural languages contain linguistically recognizable groups of organisms that vary in their inclusiveness: the most inclusive taxa (“unique beginners”) denote animals or plants in general and are divided in usually not more than six life forms such as bird, tree, mammal, or vine. Generics are the most salient entities that refer to natural kinds such as oak, pine, catfish, robin, bamboo, pineapple, platypus. Many but not necessary all generics belong to a life form. According to Berlin, generics also constitute the most numerous and important taxonomic group with usually around 500 different taxa. Some generics contain further subsets that Berlin et al. label "specific” (e.g. white oak) and "varietal taxa” (e.g. swamp white oak). To sum up, Berlin et al. postulated a universal hierarchy of folk-taxonomies as shown in Figure 1. 


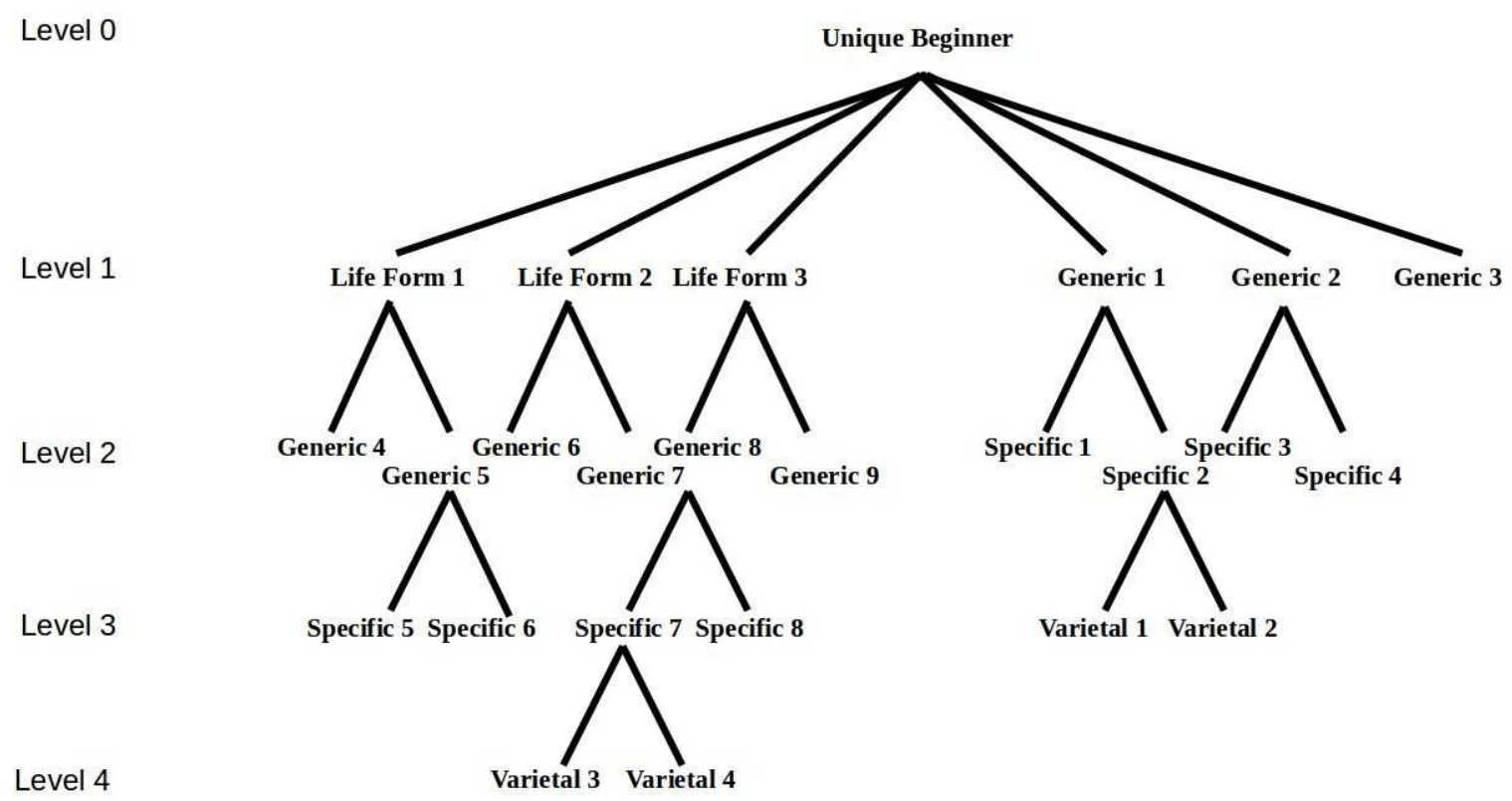

Figure 1. Schematic representation of the universal structure of folk-taxonomies according to Berlin et al.'s [1973] (figure adapted with modifications). Every folk-taxonomy starts with unique beginners (usually animal and plant) that are divided in life forms such as bird or tree. Most generics belong to some life form (level 2) but there are usually exceptions of some generics that are not classified as members of a specific life form (level 1). Salient and culturally important generics are further divided in specifics and varieties.

Although there is a clear psychological component to intellectualism that interprets cross-cultural similarities in folk-taxonomies as reflections of our evolved human cognition (cf. Atran and Medin [2010]), intellectualism traditionally prefers realism over a full-blown psychologism. The main motivation for a realist interpretation of the intellectualist tradition is that folk-taxonomies do not only tend to converge on each other but also often converge on scientific taxonomies. In one of the classical studies on this topic, Diamond [1966] reports that 85\% of 110 local bird taxa of the Fore in Papua New Guinea correspond perfectly to scientific taxa. Following the increasing influence of the intellectualist programme, ethnobiologists of the 1970s accumulated an impressive amount of data about taxonomic convergence from indigenous cultures around the globe (cf. Hunn and Brown [2011]). To illustrate this idea of convergence of indigenous and scientific taxa further, consider Berlin's presentation of ethnobiological experiments that rely on simple sorting tasks (Berlin [1992 \}, 9-10; cf. Boster [1994] and Nolan [2007] on sorting tasks in general): "Museum skins of several species of brightly colored Amazonian birds - tangers, barbets, euphonias, puffbirds - all from the rain forests of northern Peru are dumped from a basket in a heap of a table.” Berlin reports that his students produce "neatly stacked groups" that are not only remarkably consistent with each 
other but also with the stacks of ornithologists as well as the Huambisa and Aguarana Jívana in northern Peru. It certainly seems attractive to explain this agreement in terms of natural kinds: Berlin's students, ornithologists, Huambisa, and Aguarana Jívana find themselves in taxonomic agreement because they all refer to the same natural kinds.

Intellectualism and natural kind theories in the tradition of Kripke and Putnam seem to provide mutually supportive evidence for universalist realism. On the one hand, intellectualism provides empirical evidence of taxonomic convergence of indigenous and scientific kinds and even of nested hierarchies that match traditional models of natural kinds (cf. Tobin [2010]). On the other hand, natural kind theories in the tradition of Kripke and Putnam provide a philosophical explanation of convergence in terms of rigid designation of natural kinds. Upon closer observation, however, the situation is much more complicated. While intellectualism provided an important alternative to simplistic utilitarian models that explained indigenous classification entirely in terms of practical needs (e.g. “edible plants” or “dangerous spiders”), its generalization to a universalist realism is clearly too strong and the intellectualist programme of the 1970's soon became criticized for ignoring or downplaying pragmatic factors in folk-taxonomy. As Hunn put it in his influential discussion “On the Utilitarian Factor" ([1983], p. 851): "the fact that cultural knowledge of the natural world might also be of use practically has been treated as besides the point, almost an embarrassment [...] We have unduly stressed the disinterested intellectualism of our informants, and as a consequence taken for granted their practical wisdom. Pragmatism is no sin.”

If we look at the current state of ethnobiology, much of the contrast between intellectualism and utilitarianism has “faded from active academic discussions” (Zent [2009], p. 27) due to constantly growing empirical evidence of complex convergence-divergence patterns that can be neither understood in terms of purely intellectualist or utilitarian models (e.g. Souza and Begossi [2007]; Newmaster et al. [2007]; Shepard et al. [2008]; Cardoso et al. [2010]). While Zent suggests that the debate faded "without any clear resolution” ([2009], p. 27), a more charitable interpretation may be that it has become widely recognized as a false opposition: the main task for ethnobiology is not to discuss cross-culturally stable features in opposition to local factors but to integrate them in sufficiently complex models (cf. Ellen [2006], p. 2; Hunn and Meilleur [2010]).

To illustrate this need for complex models of convergence-divergence patterns, consider the example of Tzeltal Maya in Chiapas. While Berlin et al.'s work on Tzeltal ethnobotany was of crucial importance for the intellectualist programme, it did not provide evidence for perfect taxonomic convergence. Instead, Berlin et al. ([1974], p. 102), report that 61\% of Tzeltal plant generics correspond to scientific species. In a similar vain, Hunn ([1976]; cf. Hunn and Brown [2011]) reports 1:1 correspondences of 44\% - 92\% between Tzeltal animal generics and scientific taxa depending on a variety of methodological adjustments. More recently, Tzeltal ethnomycology 
has become more carefully studied and clearly illustrates the shortcomings of purely intellectualist or utilitarian models (Lampman [2004]; Shepard et al. [2008]). While some of the most salient mushroom-generics correspond neatly with a single scientific genus or family, other ethnomycological taxa diverge from scientific taxonomies in the most obvious ways. For example, macrofungi are divided in two life forms of either “(1) fleshy terrestrial mushrooms; (2) and mushrooms that grow on trees or rotting wood” (Shepard et al. [2008]; 451). Furthermore, obvious taxonomic divergence is not limited to the rank of life form but also applies to some folk-generics such as k'aan chay that includes a group of mushrooms (chanterelles, milk cups, hedgehogs) that is rather heterogeneous from a scientific perspective.

What does this recognition of complex convergence-divergence patterns mean for a philosophical discussion of natural kinds? While the assumption of rigid designation of natural kinds such as tigers may be helpful in understanding some indigenous taxa that converge on scientific taxa, it clearly does not generalize to universalist realism. For example, it is highly implausible to interpret Tzeltal ethnomycological life forms or generics such as k'an chay in terms a universalist realism because they do not converge on scientific taxa. Note that it will not help to point out that rigid designators can successfully refer despite limited or false beliefs about natural kinds such as tigers. In some cases such as my ethnomycological examples, divergence clearly runs deeper and seems to imply at some form of "taxonomic incommensurability" (cf. Sankey [1998]) due to the lack of extensionally equivalent scientific kinds.

\section{Revisionism}

Universalist realism fails to offer a satisfying interpretation of convergence-divergence patterns in ethnobiology due to its inability to explain substantive forms of taxonomic divergence. One way of responding to these the limitations is to endorse a revisionist account of indigenous kinds whenever we find genuine taxonomic disagreement. For example, one could argue that the importance of utilitarian factors in folk-biological classification shows that indigenous taxa often do not "carve nature at its joints" because they reflect pragmatic and culturally relative interests. Note that "revisionism" in this context has no practical implications such as the suggestion that indigenous folk-biologists should adopt scientific taxonomies and eliminate utilitarian considerations. Instead, revisionism makes the metaphysical claim that indigenous kinds qualify as natural kinds only if they converge on scientific kinds.

Revisionism in this sense seems to be endorsed by parts of the current philosophical literature on natural kinds. For example, Khalidi ([2013]; p. 59) suggests that “folk categories can be expected either to coincide with or to be superseded by scientific categories when the purposes for which 
they are introduced are roughly the same.” Khalidi also acknowledges folk-categories that are shaped by utilitarian purposes and still co-exist with scientific taxa but he argues that they do not qualify as natural kinds: "Speaking generally, it is quite possible that we might introduce categories that enable us to serve certain desired aims, but do not correspond to the kinds that exist in nature. In such cases, since there is no direct competition between folk categories and scientific categories, we would expect the folk categories to coexist alongside scientific ones. But such folk categories should not be expected to correspond to natural kinds” ([2013], p. 60). In addition to utilitarian factors, revisionists may also point to evolutionary considerations according to which folkcategories are adaptive but often fail to reflect the causal mechanisms that constitute natural kinds. For example, de Cruz and Smedt ([2006], p. 364) argue that "lay adults view the world in terms of intuitive ontologies. While these provide a shallow but fast framework to explain and understand salient features of the environment, they are epistemologically limited.”

Given that large parts of the current philosophical literature discuss natural kinds as a subset of scientific kinds (e.g. Ereshefsky and Reydon [2014]; Magnus [2012]), one may interpret revisionism as the default position in contemporary philosophy of science. However, few philosophers of science explicitly engage with folk kinds and it may be uncharitable to interpret them as revisionists. For example, one can avoid revisionism by supplementing the claim that all natural kinds are scientific kinds with a deflationist reading of "science” that includes indigenous folk-biologies and other “ethnosciences” (e.g. Lévi-Strauss [1962]; Gorelick [2014]: cf. Magnus [2012], chapter 5). Whether widely endorsed or not, the crucial question in the current context is whether revisionism is a plausible position. Prima facie, the incorporation of utilitarian elements and "special purpose” categories (Berlin et al. [1973]; cf. Ellen [2006], pp. 124-126) in traditional intellectualist accounts give this strategy some initial plausibility. At least some indigenous categories are shaped by very specific utilitarian concerns and have little use beyond its satisfaction of a restricted cultural need. For example, Shepard et al. [2008] report bol lu' as an all-purpose Tzeltal category of inedible, poisonous, and unknown mushrooms.

However, not all cases of taxonomic divergence can be explained though obvious utilitarian concerns. Let us consider an example that will elicit revisionist intuitions of many philosophers: the common (e.g. Atran [1998]; Forth [2010]) assumption of a taxon with the extension of bats and birds. While such a bat-bird taxon differs from bol $l u^{\prime}$ in not being reducible to obvious utilitarian concerns, one may justify revisionist intuitions by arguing that such a taxon only reflects one superficial property (the ability to fly) instead of real biological discontinuities that characterize genuine natural kinds. However, this response is insufficient as it ignores the wide range of properties that are typically shared by bats and birds. For example, both typically fly, have wings, a light bone-structure, a keeled sternum, a similar size range, streamlined bodies, high metabolism, 
migratory behavior, similar natural enemies, a fruit and insect-based diet, they disperse seeds in the environment, reduce local insect biomass, and so on. Atran [1998] shows that Itza' Maya in northern Guatemala classify bats with birds (ch'iich') and argues that Itza' taxonomy is strongly influenced by ecological relations that contrast with traditional western focus on the internal structure of organisms. Note that similar ecological roles of bats and birds are not limited to rather generic characterizations such as "seed dispersal" but can be applied to highly specific ecological relations such as the density of ramon around Maya ruins that it "may owe more to [...] seed dispersal by bats inhabiting the ruins than to artificial selection by Maya” (Atran [1993], p. 636).

Even if folk-taxa diverge from scientific taxa, they often share a wide range of properties and not only a specific utilitarian property such as being inedible. This observation is reflected by complex models in contemporary ethnobiology such as Newmaster et al.'s [2007] "multi-mechanistic" approach to ethnobotany of the Irulas in Southern India that identifies three taxonomic primary mechanisms (morphology, ecology, and experience) as well as different types of utilitarian secondary mechanisms (e.g. nutritional, medicinal, technical or ritual). Even if these mechanisms are complex, they clearly differ from scientific criteria and therefore do not lead to universal taxonomic convergence. One of the most widely discussed aspects of indigenous taxonomies is their focus on ecological relations instead of internal structural properties. Assuming that indigenous folk-biologists "concentrate on functional relationships and coevolutionary processes rather than internal structure” (Pierotti [2011], p. 67), substantial taxonomic divergence is an unsurprising consequence. In response, a revisionist would have to argue that Itza' somehow focus on the wrong properties and therefore fail to recognize genuine natural kinds. However, even in the case of a bat-bird taxon, it is not immediately clear how this should work. Arguably, the shared properties of bats and birds are perfectly real, epistemically significant, and more important than structural similarities relative to the priorities of Itza'.

In considering possible revisionist responses, let us first get two obvious non-starters out of the way. First, one may follow traditional natural kind essentialism by requiring intrinsic essences instead of relational properties such as ecological roles. The obvious problem with this strategy is that it has become a truism in philosophy of biology that essentialism is wrong. Indeed, many philosophers have argued that we only have to give up the assumption of intrinsic essences (e.g. Okasha [2002]; LaPorte [2004]) but the alternative of relational essences is compatible with the assumption that indigenous kinds also have essences. Second, one may reject indigenous kinds that rely on ecological considerations on the basis of some general notion of overall-similarity and argue for the priority of structural similarity. However, there is no reason why indigenous folk-biologists should agree with the similarity intuitions of revisionists. Furthermore, an account that relies on structural similarities is also a clear non-starter in contemporary biology given structural differences between 
members of the same species with sexual polymorphism (Ereshefsky and Matthen [2005]; Magnus [2014]) or between many members of the same monophyletic higher taxon (cf. Rieppel [2005]; Boyd [2010]).

A more promising revisionist strategy relies on the widely shared belief that natural kinds must support diverse inductive inferences (cf. Häggqvist [2005]). To know that an organism $x$ is a member of the scientific taxon $\mathrm{T}$ means that we know a lot about $\mathrm{x}$ - about its history, genes, anatomy, physiology, behavior, and so on. To know that a mushroom is bol lu' only means that we can't eat it. However, I have already argued that it is a mistake to assimilate all indigenous taxa that diverge from scientific taxa to utilitarian categories such as bol lu'. Instead, it seems highly plausible that indigenous taxa usually support a wide variety of inductive inferences because they typically rely on "multi-mechanistic" criteria in the sense of Newmaster et al. [2007] and reflect deep knowledge about local environments and ecological dynamics. Furthermore, research in cognitive science provide direct evidence for the inductive potential of indigenous folk-taxa. For example, Bailenson et al. ([2002]; cf. Atran and Medin [2010], p. 86) tested cross-cultural differences in inductive reasoning about birds and showed that Itza' resemble western experts in relying on complex inductive strategies even if their reasoning differs in being strongly influenced by ecological reasoning. In fact, it is often noted that indigenous folk-biologists can be more successful than western biologists in predicting and explaining local ecological phenomena (e.g. Pierotti [2011]). Of course, much more can and should be said about the inductive potentials of kinds. I will return to this issue in my positive model (section 4 \& 5) that involves "stable property clusters" and probabilistic inferences between sub-clusters. Before we address these issues in more detail, however, let us consider a third simple model of the relation between indigenous and scientific taxa: conventionalism.

\section{Conventionalism}

Given that neither universalism nor revisionism (nor a combination of both) provides an adequate account of convergence-divergence patterns, one may interpret ethnobiological evidence as challenging the very idea of natural kinds. Maybe, the difficulties are the result of an overly ambitious metaphysics that misunderstands human classification as a mirror of the objective structure of the biological realm. As soon as we give up on natural kinds, the whole problem disappears because we can simply accept that the range of human classifications is just as broad and variable as the range of human interests and preferences.

If we look for philosophical support of this position, it is important to distinguish between two positions: pluralism and conventionalism. Taxonomic or classificatory pluralism is widely endorsed 
in various areas of philosophy of biology (e.g. Bapteste and Dupré [2013], Barker and Velasco [2013], Ludwig [2013], Winther [2011]) and my own model of sections 4 and 5 will also turn out to be thoroughly pluralistic. However, classificatory pluralism in its most general sense only claims that there is not exactly one fundamental classification but it does not provide a positive model of convergence-divergence patterns. One possible specification is a conventionalist pluralism that claims that the only standards for the evaluation of taxonomies are conventions that reflect our contingent interests and purposes. For example, Kitcher ([2008], p. 119) argues that there is "no higher standard to which our concepts are to answer than the efficient satisfaction of the purposes of inquiry; those purposes are set, not by nature, but by us.” Applied to ethnobiology, conventionalism has the obvious advantage of explaining taxonomic divergence. As Dupré [1999] puts it: “there is no reason to expect folk biological kinds to converge towards scientifically recognized kinds.”

However, there is an obvious problem with this suggestion: even if conventionalists assure us that we do not have to expect convergence, ethnobiology provides countless examples of convergence of indigenous and scientific taxa. In some areas such as highly salient vertebrate species, extensional agreement between folk-biological generics and scientific taxa can be higher than 90\% (Hunn and Brown [2011]). A conventionalist may respond to these findings by arguing that complex convergence-divergence patterns in taxonomy simply reflect equally complex similarities and differences between our interests. Indigenous and scientific taxa often converge because the interests and therefore the classificatory conventions of folk-biologists and scientists often converge.

Unfortunately, this response will not work. Following Slater [2014], let us assume that a biological kind $\Phi$ (e.g. jaguar) comes with a number of (e.g. morphological, behavioural, genetic...) properties such as P, Q, R, S, T. Furthermore, let us use brackets (e.g. [Ф] or [P, Q, R, S, T]) to indicate clustering of properties. In order to make this notation applicable to a comparative discussion of multiple taxonomies, let us add indices such as $[\mathrm{P}, \mathrm{Q}, \mathrm{R}]_{\mathrm{i}}$ or $[\mathrm{P}, \mathrm{Q}, \mathrm{S}, \mathrm{T}]_{\mathrm{s}}$ for property clusters that are recognized in different contexts (e.g. by indigenous folk-biologists and scientists). For example, let us assume that Itza' Maya and zoologists both recognize a morphological (P) and a behavioural (Q) property of jaguars, while only Itza' recognize an ecological property (R) and only zoologists recognize a genetic (S) as well as a phylogenetic (T) property. In this case, $\Phi$ would come with the cluster $[\mathrm{P}, \mathrm{Q}, \mathrm{R}, \mathrm{S}, \mathrm{T}]$ and the recognized sub-clusters $[\mathrm{P}, \mathrm{Q}, \mathrm{R}]_{\mathrm{i}}$ and $[\mathrm{P}, \mathrm{Q}, \mathrm{S}, \mathrm{T}]_{\mathrm{s}}$.

In explaining taxonomic convergence, a conventionalist can argue that relations between indigenous and scientific taxa will often resemble this example of $[\mathrm{P}, \mathrm{Q}, \mathrm{R}]_{\mathrm{i}}$ and $[\mathrm{P}, \mathrm{Q}, \mathrm{S}, \mathrm{T}]_{\mathrm{S}}$ in the sense that recognized sub-cluster will overlap to some degree due to overlapping interests between folkbiologists and modern scientists. To illustrate how this can explain convergence, let us consider three stamp-collectors who employ different conventions in classifying stamps. Collector A 
classifies her stamps by considering their country of origin, issue date, and value while B considers country of origin, issue date, and shape. Given the overlap between the classificatory conventions, we should expect at least some convergence of classifications of A and B. In contrast, imagine that C classifies stamps only on the basis of colour. Given that there is no overlap between the conventions that are used by $\mathrm{C}$ and by $\mathrm{A} / \mathrm{B}$, it would not be surprising if their classifications diverge. In analogy, a conventionalist can claim that convergence-divergence patterns are due to the partial overlap of interest-relative conventions: indigenous and scientific taxa simply overlap to the degree that the sets of considered properties overlap.

A closer look at the ethnobiological data, however, illustrates that this analogy does not work. First, ethnobiologists often find a surprising number of 1:1 correspondences between folk-biological and scientific taxa such as the 92\% that are reported by Hunn ([1975]; cf. Hunn and Brown [2011]) in the case of Tzeltal vertebrate generics. However, these 1:1 correspondences do not indicate that Tzeltal folk-biologists and zoologists focus on near-identical properties. Second, we can also find taxonomic convergence without any overlap of considered properties whatsoever. Consider jaguars as one of the countless examples of 1:1 taxonomic correspondence between modern biological species (e.g. Panthera onca) and folk generics (e.g. b'alum, chak mo'ol, chak bolay, cf. Schlesinger [2001]). Even if the properties that are recognized by an indigenous folk-biologist $\left([\mathrm{P}, \mathrm{Q}, \mathrm{R}]_{\mathrm{i}}\right)$ and a scientist ([P, Q, S, T $]_{\mathrm{s}}$ ) partly overlap, we can at least imagine a purely utilitarian taxonomy that relies entirely on non-overlapping criteria such as likelihood of being attacked (U) or appropriate behavior in encounters (V). However, even this utilitarian classification that only serves the purpose of avoiding dangerous animals would arguably identify jaguars as a taxon that is extensionally equivalent to Panthera onca. In other words: we would find convergence despite no overlap in the sets of considered properties. The zoologist recognizes $[\mathrm{P}, \mathrm{Q}, \mathrm{S}, \mathrm{T}]_{\mathrm{s}}$ while the utilitarian taxonomist recognizes $[\mathrm{U}, \mathrm{V}]_{\mathrm{u}}$. Still, both end up with extensional agreement and refer to jaguars who typically have the properties $[\mathrm{P}, \mathrm{Q}, \mathrm{R}, \mathrm{S}, \mathrm{T}, \mathrm{U}, \mathrm{V}]$. While this result clearly illustrates the limitations of conventionalism, it also provides the starting point for a more satisfying model of convergencedivergence patterns that I will spell out in the next section: biological properties are not randomly distributed but clustered in a way that knowledge about some properties such as $\mathrm{U}, \mathrm{V}$ gives us good reasons to expect other properties such as $\mathrm{P}, \mathrm{Q}, \mathrm{S}, \mathrm{T}$.

\section{A Model of Convergence-Divergence Patterns}

While the idea of property clustering is most prominently discussed in "homeostatic property cluster” theories (Boyd [1999]; Craver [2009], Wilson et al. [2007]), I will follow Slater's [2014] theoretically more modest account of "stable property clusters" (SPC) that avoids commitment to 
underlying homeostatic mechanisms or alternative explanations of why property clustering occurs. The core of Slater's account is the idea that some property clusters are "cliquishly stable" in the sense that "possession of some [properties] reliably (if imperfectly) indicates the possession of the whole cluster” [2014]. Consider Slater's example of a clique of Peg, Quinn, Ralph, Sarah, and Tim. Spotting some of them at the mall gives us good reason to expect the others at the mall, as well. For example, if we spot the sub-clique [Peg, Quinn, Ralph], we have good reasons to expect the subclique [Sarah, Tim] to be there as well. Following Slater, we can define cliquish SPCs by introducing a number of sub-clusters $\left[\Phi_{1}\right],\left[\Phi_{2}\right],\left[\Phi_{3}\right] \ldots$, a notation for probabilistic entailment $\Rightarrow$, and a robustness operator $\mathbf{m}$. $\Phi$ will be a cliquish SPC, iff for every x and many sub-clusters:

- $\left(\left(\left[\Phi_{1}\right] \mathrm{x} \Rightarrow[\Phi]\right) \wedge\left(\left[\Phi_{2}\right] \mathrm{x} \Rightarrow[\Phi]\right) \wedge\left(\left[\Phi_{3}\right] \mathrm{x} \Rightarrow[\Phi]\right) \wedge \ldots\right)$

The assumption that property clusters exhibit cliquish stability provides a much better explanation of taxonomic convergence than the conventionalist model that relies on a partial overlap between the recognized properties in $[\Phi]_{\mathrm{i}}$ and $[\Phi]_{\mathrm{s}}$. Let us return to the example of jaguars and the assumption of three taxonomies that consider different properties: An indigenous folk-biologist recognizes the sub-cluster $[\mathrm{P}, \mathrm{Q}, \mathrm{R}]_{\mathrm{i}}$, a zoologist recognizes $[\mathrm{P}, \mathrm{Q}, \mathrm{S}, \mathrm{T}]_{\mathrm{s}}$, and our imagined utilitarian taxonomist recognizes $[\mathrm{U}, \mathrm{V}]_{\mathrm{u}}$. While the conventionalist model fails to explain taxonomic convergence in this case due to the lack of overlap between $[\mathrm{U}, \mathrm{V}]_{\mathrm{u}}$ and $[\mathrm{P}, \mathrm{Q}, \mathrm{R}]_{\mathrm{i}} /[\mathrm{P}, \mathrm{Q}$, $\mathrm{S}, \mathrm{T}]_{\mathrm{s}}$, the idea of cliquish SPCs offers an obvious explanation. Assuming a sufficiently robust cliquishness of the considered properties, we can easily explain cross-cultural convergence of taxonomies as it is true that for every $\mathrm{x}$ :

- $\left(\left([\mathrm{P}, \mathrm{Q}, \mathrm{R}]_{\mathrm{i}} \mathrm{X}=[\Phi]\right) \wedge\left([\mathrm{P}, \mathrm{Q}, \mathrm{S}, \mathrm{T}]_{\mathrm{S}} \mathrm{X} \Rightarrow[\Phi]\right) \wedge\left([\mathrm{U}, \mathrm{V}]_{\mathrm{U}}=[\Phi]\right)\right)$

This idea of cliquish SPCs provides a convenient explanation for the convergence of taxonomies even in cases where there is no overlap between recognized properties because the presence of one recognized sub-cluster allows a probabilistic inference to the presence of another non-recognized sub-cluster, so that for every $\mathrm{x}$ :

- $\left.\left(\left([\mathrm{P}, \mathrm{Q}, \mathrm{R}]_{\mathrm{i}} \mathrm{x} \Leftrightarrow[\mathrm{P}, \mathrm{Q}, \mathrm{S}, \mathrm{T}]_{\mathrm{S}} \mathrm{x}\right) \wedge\left([\mathrm{P}, \mathrm{Q}, \mathrm{R}]_{\mathrm{i}} \mathrm{x} \Leftrightarrow[\mathrm{U}, \mathrm{V}]_{\mathrm{u}} \mathrm{x}\right)\right) \wedge\left([\mathrm{U}, \mathrm{V}]_{\mathrm{u}} \mathrm{x} \Leftrightarrow[\mathrm{P}, \mathrm{Q}, \mathrm{S}, \mathrm{T}]_{\mathrm{s}} \mathrm{x}\right)\right)$

This idea of cliquish property clustering does not only explain taxonomic convergence but is also attractive in other areas of ethnobiology. For example, consider debates about "traditional ecological knowledge” (TEK) and its integration with scientific knowledge (Huntington [2000]). 
Cliquish property clustering provides a convenient model for at least some types of integration of TEK and scientific knowledge: On the one hand, TEK often incorporates knowledge about properties that are not recognized by scientists who are not as intimately familiar with populations in local environments. On the other hand, scientists will often have knowledge about the same organisms that is not part of TEK. If both sides have knowledge about different properties of the same property cluster, both types of knowledge are clearly commensurable as we can make inferences from one sub-cluster to another $\left([\Phi]_{\mathrm{TЕK}} \mathrm{X} \Leftrightarrow[\Phi]_{\mathrm{s}} \mathrm{X}\right)$. For example, TEK about local nesting places of birds (Gilchrist et al. [2005]) or migratory behavior of beluga whales (Huntington [2000]) will integrate with scientific knowledge about the same birds or whales because they constitute different types of knowledge about the same SPCs.

Even if the idea of cliquish SPCs offers a helpful model of convergence, integration of TEK and scientific knowledge will not always be smooth and can also turn out to be impossible. Although this article barely touches the wider context of taxonomic divergence through embedding in “assemblages of heterogeneous practices” (Watson-Verran and Turnbull [1995], p. 118; cf. Deleuze and Guattari [1980] for the notion of “assemblages”), a comprehensive model will have to leave room for various sources of divergence from slight differences in explanatory interests to radically different social contexts such as stateless tribal polities in New Guinea (Sillitoe [2002]) and modern biopolitics (e.g. Foucault [2006]). While my abstract formulation of a SPC-based model does not spell out these complex factors, it leaves room for at least four sources of taxonomic divergence.

First, taxonomic divergence can occur because a category does not refer to a SPC at all. Think of Tzeltal ethnomycological category of bol $l u^{\prime}$ as an all-purpose category for inedible, poisonous, and unknown mushrooms. Members of the bol $l u^{\prime}$ category arguably do not form a stable property cluster that would allow us to make probabilistic inferences from one sub-cluster to another as macrofungi of the bol llu' category only share the property of being useless to Tzeltal. More generally, we will find many categories that involve socially important properties but do not constitute SPCs and therefore give us no reason to expect taxonomic convergence.

Second, taxonomic divergence can occur because only indigenous folk-biologists or scientists have knowledge of a SPC. For example, Newmaster and Ragupathy's [2010] propose an "ethnobotany genomics" that relies on DNA barcoding methods as a common tool for plant identification. In one of their studies, Ragupathy et el. [2009] focused on the grass genus Tripogon in the Western Ghats of southern India and compared scientific knowledge with TEK of local Irula informants. The research not only revealed slight taxonomic differences (seven species according to scientific knowledge, eight according to local TEK) but subsequent DNA barcording identified the scientifically unrecognized taxon sunai pul as a separate species (Tripogon cope). In clear contrast to bol lu', taxonomic convergence in this case was not due to a lack of stable property clustering but 
through limited scientific knowledge.

Third, taxonomies can diverge because a SPC is recognized but not considered relevant from either indigenous or scientific perspective. For example, recall my example of a bat-bird taxon. I have argued that bats and birds share a large variety of properties and its plausible to assume that they constitute a SPC that it is at least somewhat cliquishly stable due to convergent evolution of powered flight and adaption to a flying lifestyle. Modern scientists may acknowledge this clustering but not deem it of taxonomic importance.

Fourth, Slater's framework of SPC suggests a less obvious but highly relevant source of taxonomic divergence. Recall that SPCs require a sufficiently robust form of cliquishness. Clearly, we should not require that cliquish stability holds in all (empirically or even logically) possible situations as there may very well be circumstances in which cliquish stability breaks down. For example, consider a medical kind and the relation between symptoms [A, B, C] and underlying causes [D, E]. Under normal circumstances, $[\mathrm{A}, \mathrm{B}, \mathrm{C}, \mathrm{D}, \mathrm{E}]$ come as a clique so that we can use $[\mathrm{A}, \mathrm{B}, \mathrm{C}]$ as an indicator for [D, E] and vice versa. Let us assume, however, that medical treatment breaks the clique apart by suppressing the symptoms without treating the underlying causes. Still, it seems to reasonable to consider [A, B, C, D, E] a cliquish SPC. Even if SPCs do not have to exhibit cliquishness under all circumstances, however, we do want to cliquishness to be sufficiently robust in relevant circumstances. For example, if symptoms $[\mathrm{A}, \mathrm{B}, \mathrm{C}]$ indicate the presence of $[\mathrm{D}, \mathrm{E}]$ only under very specific circumstances we would not want to consider [A, B, C, D, E] as a cliquish SPC in general.

How do we distinguish between relevant and irrelevant circumstances? Slater suggests that this question has to be ultimately answered relative to domains of inquiry in the sense that property clusters "are cliquishly stable for a given science, project, research programme, or what have you" [2014]. Ethnobiology arguably provides an abundance of examples for domain-relativity as debates about “local ecological knowledge” (LEK) illustrate (e.g. Gilchrist [2005], Anadón [2009], Davis and Ruddle [2010]). For example, consider my earlier example of Tzeltal ethnomycology. Even if bol lu' does not qualify as a SPC, other taxa may refer to property clusters that are cliquishly stable in the domain of Tzeltal mycology.

Consider the Tzeltal mushroom taxon tsa' wakax that does not correspond with any taxon in scientific mycology (Lampman 2004). Members of this taxon usually share a number of properties such as being small, of brownish color, short-lived, inedible, having gills, well-developed stipes, thin stalks, they grow on grasslands, shrivel up in the sun, have no cultural use, are found between June and October, and so on. Tsa' wakax is a SPC for the domain of Tzeltal ethnomycology if subclusters (say [brownish color, thin stalk, grows grasslands] or [short-lived, gills, well-developed stipe, found in July]) allow a probabilistic inference to tsa' wakax in general and therefore to other 
properties that are associated with tsa' wakax (e.g. being inedible, not found in spring). However, that does not mean that tsa' wakax also qualifies as a SPC in the domain of scientific mycology. If we consider the range of circumstances that are relevant for a mycologist who is not exclusively interested in the highlands of Chiapas, the cliquish stability of the mentioned properties arguably breaks down as there will be environments in which [brownish color, thin stalk, grows grasslands] or [short-lived, gills, well-developed stipe, found in July] is not a reliable indicator for the other properties that are associated with tsa' wakax. In other words: $t s a^{\prime}$ wakax may be a SPC relative to the domain of Tzeltal ethnomycology but is arguably not a SPC relative to the domain of scientific mycology. Or, more generally: given that indigenous taxonomies are at least partly shaped by a highly specific LEK that is adapted to its unique environment, we can predict that many taxa will be cliquishly-stable only relative to this specific LEK-domain.

\section{Domain-Transcendence and Categorical Bottlenecks}

In the last section, I argued that cliquish SPCs allow us to understand convergence-divergence patterns in ethnobiology. While convergence is understood through the cliquish-stable clustering of properties, there remain various sources of taxonomic divergence. However, one may worry that the different parts of my model do not fit together. In the beginning of the last section, I suggested that cliquish-stable clustering of properties can ensure taxonomic convergence across domains of inquiry. A zoologist may recognize the sub-cluster $[\mathrm{P}, \mathrm{Q}, \mathrm{S}, \mathrm{T}]$ of a kind such as jaguar but not $[\mathrm{P}, \mathrm{Q}$, $\mathrm{R}$ ] while an Itza' recognizes [P, Q, R] but not [P, Q, S, T]. However, their taxonomies still converge because $[\mathrm{P}, \mathrm{Q}, \mathrm{R}, \mathrm{S}, \mathrm{T}]$ is a domain-transcending clique. If we can understand cliquishness only relative to a domain of inquiry, however, it becomes unclear how we can make sense of cliquish stability of [P, Q, R, S, T] across domains of inquiry.

In order to understand taxonomic convergence despite domain-relativity, let us return to the example of jaguars and the observation that jaguars are recognized by both Itza' and zoologists. Let us assume that Itza' recognize a number of (e.g. morphological, behavioural, ecological...) property sub-clusters $\left[\Phi_{1}\right]_{\mathrm{i}},\left[\Phi_{2}\right]_{\mathrm{i}},\left[\Phi_{3}\right]_{\mathrm{i}} .$. that are reliable predictors for jaguars given the set of circumstances $\left(\mathrm{C}_{\mathrm{i} 1}, \mathrm{C}_{\mathrm{i} 2}, \mathrm{C}_{\mathrm{i} 3} \ldots\right)$ that are relevant to Itza'. Following the idea of domain-relative SPCs, jaguar is a SPC for the domain of Itza' folk-biology as for every $\mathrm{x}$ :

$\left(\left(\mathrm{C}_{\mathrm{i} 1} \vee \mathrm{C}_{\mathrm{i} 2} \vee \mathrm{C}_{\mathrm{i} 3} \ldots\right) \rightarrow\left(\left(\left[\Phi_{1}\right]_{\mathrm{i}} \Rightarrow[\Phi]\right) \wedge\left(\left[\Phi_{2}\right]_{\mathrm{i}} \mathrm{X} \Rightarrow[\Phi]\right) \wedge\left(\left[\Phi_{3}\right]_{\mathrm{i}} \mathrm{X} \Rightarrow[\Phi]\right) \wedge \ldots\right)\right.$

This formulation can be easily modified to incorporate cross-domain stability. Let us assume that modern zoologists consider the set of circumstances $\left(C_{s 1}, C_{s 2}, C_{s 3} \ldots\right)$ relevant. The set of 
circumstances that is relevant to zoologists may be considerable larger than the set of circumstances that is relevant to Itza'. For example, it will also include environmental conditions that are only found in South American habitats of jaguars and are therefore not relevant to Itza'. Even if we consider the broader set of circumstances that are relevant to zoologists, however, it may still turn out that many of the sub-clusters that recognized by Itza' remain reliable indicators for jaguars. In this case, the conditional remains true if we replace the circumstances that are relevant to Itza' with the circumstances that are relevant to zoologists, so that for every $\mathrm{x}$ :

$\left(\left(\mathrm{C}_{\mathrm{s} 1} \vee \mathrm{C}_{\mathrm{s} 2}, \vee \mathrm{C}_{\mathrm{s} 3} ..\right) \rightarrow\left(\left(\left[\Phi_{1}\right]_{\mathrm{i}} \mathrm{x} \Rightarrow[\Phi]\right) \wedge\left(\left[\Phi_{2}\right]_{\mathrm{i}} \mathrm{x} \Rightarrow[\Phi]\right) \wedge\left(\left[\Phi_{3}\right]_{\mathrm{i}} \mathrm{X} \Rightarrow[\Phi]\right) \wedge \ldots\right)\right.$

The robust cliquishness of a SPC relative to an alternative set of circumstances illustrates the possibility of a domain-transcending SPC. $\Phi$ is a domain-transcending SPC for a range of domains $d_{1}, d_{2} \ldots d_{n}$ iff cliquish stability remains robust across the circumstances that are relevant for the entire range of domains. For example, jaguar is a domain-transcending SPC for the domains of Itza' folk-biology and modern zoology because some sub-clusters that are recognized by Itza' will reliably pick out jaguars under the circumstances that are considered relevant for zoologists (and vice versa). For example, a cluster of morphological and/or behavioural properties of jaguars that are recognized by Itza' would also serve as a reliable indicator for jaguars in South American environments that are relevant to modern zoologists but not to Itza'. In contrast, taxa that are unique in a specific LEK such as ethnomycological taxon tsa' wakax may not be a domain-transcending SPC for a range of domains that also includes modern mycologists because the cliquish stability breaks down in environments that are not relevant to the LEK of Tzeltal Maya.

While the distinction between between domain-relative and domain-transcending SPCs is helpful for a discussion of the relation between taxonomies, it is unfortunately not sufficient to explain convergence-divergence patterns. For example, recall my incomplete list of properties that are typically shared by bats and birds: they fly, have wings, a light bone-structure, a keeled sternum, a similar size range, streamlined bodies, high metabolism, migratory behavior, similar natural enemies, a fruit and/or insect-based diet, they spread seeds in the environment, reduce local insect biomass, and so on. I suggested that a bat-bird taxon may qualify as a SPC for Itza' Maya due to the cliquish clustering of properties that are the result of convergent evolution. Contrary to the ethnomycological Tzeltal taxon tsa' wakax, however, a bird-bat taxon is recognized by many societies around the globe and arguably not only robust in circumstances that are relevant to Itza'. It may therefore turn out that a bat-bird taxon refers to a domain-transcending SPC.

Even if a bat-bird taxon refers to a domain-transcending SPC, however, zoologists will deny its taxonomic relevance and may even reject it as paradigmatic case of a classification that is 
epistemologically dubious because it conflicts with the study of evolution (cf. Love 2008). In contrast, Itza' may consider shared properties (e.g. ecological roles) of bats and birds more significant than the structural or evolutionary similarities between bats and other mammals (cf. Atran 1998). If a bat-bird taxon refers to a domain-transcending SPC, we have to acknowledge that only some domain-transcending SPCs actually lead to taxonomic convergence. In the following, I will assume that taxonomic convergence requires not only domain-transcending cliquishness but also domain-transcending epistemic relevance. If a SPC satisfies this additional epistemic criterion, I will call it a "bottleneck SPC.” The notion of a bottleneck follows Franklin-Hall's [2014] recent suggestion that we should understand natural kinds as "categorical bottlenecks" that "not only best serve us, with our idiosyncratic aims and cognitive capacities, but also those of a wide range of alternative agents.”

Before we have a closer look at some of the philosophical implications of this combination of SPCs and categorical bottlenecks, let us quickly get a terminological issue out of the way. While Slater [2014] talks about domains of inquiry, Franklin-Hall focuses on agents with different aims and capacities. There may be important differences between both formulations but at least for the sake of my present discussion, I will assume that different domains in the sense of Slater come with different agents in the sense of Franklin-Hall. If a SPC is cliquishly stable for a chosen range of domains (e.g. Itza' folk-biology and zoology) it is also cliquishly stable for a corresponding range of agents (e.g. Itza' folk-biologists and zoologists). Franklin-Hall's notion of agents may be more finegrained in the sense that a domain of inquiry may come with agents who have different aims but for now that does not matter.

The idea that only some domain-transcending SPCs qualify as categorical bottlenecks is clearly helpful for a discussion of examples such as my bat-bird taxon. Even if a bat-bird taxon qualifies as a domain-transcending SPC, it clearly doesn't serve the epistemic aims of most biologists and therefore fails to satisfy Franklin-Hall's characterization. This does not mean that a bat-bird taxon does not serve any epistemic aims whatsoever. Given that the epistemic aims of Itza' (and many other indigenous societies) importantly include the understanding of ecological relations but do not not include understanding of genetic or phylogenetic properties, a bat-bird taxon appears perfectly legitimate.

To sum up, it seems that we should distinguish between three types of SPCs: (a) local SPCs that are cliquishly stable for a given domain, (b) domain-transcending SPCs that are cliquishly stable across a range of domains, (c) bottleneck SPCs that are that are cliquishly stable and serve epistemic aims of inquirers across a range of domains. With this fully developed SPC-based model, we clearly have an account of convergence-divergence patterns that is vastly superior to the simple models that I discussed in the first half of the article. Like universalism, the SPC-based model explains 
convergence of indigenous and scientific taxonomies but it also leaves room for substantial taxonomic divergence. Like revisionism, the SPC-based model allows that some folk-biological categories such as bol lu' are "merely" utilitarian but it also leaves room for diverging indigenous taxa that incorporate complex knowledge about the structure of the biological realm. Like conventionalism, the SPC-based model stresses the importance of contingent and culture-relative factors but it does not reduce classifications to conventions. By avoiding the limitations of these simple models, the SPC-based account offers a nuanced picture that provides a variety of explanations for different convergence-divergence patterns (cf. Table 2).

\begin{tabular}{|c|c|c|c|c|c|}
\hline & $\begin{array}{l}\text { Jaguar (b'alum, } \\
\text { Panthera } \\
\text { onca...) }\end{array}$ & $\begin{array}{l}\text { sunai pul, } \\
\text { Tripogon cope }\end{array}$ & $\begin{array}{l}\text { Bat-Bird } \\
\left(\text { ch'iich'..) }^{\prime}\right.\end{array}$ & tsa' wakax & bol lu' \\
\hline SPC in one domain & $\mathrm{x}$ & $\mathrm{x}$ & $\mathrm{x}$ & $\mathrm{x}$ & \\
\hline $\begin{array}{l}\text { SPC in several } \\
\text { domains }\end{array}$ & $\mathrm{x}$ & $\mathrm{x}$ & $\mathrm{x}$ & & \\
\hline Bottleneck SPC & $\mathrm{x}$ & $\mathrm{x}$ & & & \\
\hline
\end{tabular}

Table 2: Five taxa discussed in sections $4 \& 5$ relative to a range of domains that includes various indigenous (Itza', Tzeltal, Irula) and scientific domains of inquiry.

\section{Convergence and Natural Kindness}

In the past two sections, I used Slater's account of cliquish SPCs and Franklin-Hall's account of “categorical bottlenecks" to develop a model of taxonomic convergence-divergence patterns that sheds light on the relation between indigenous and scientific kinds. Even if engagement with recent ethnobiological research is an interesting (and so far almost non-existent) project in philosophy of science, Slater's and Franklin-Hall's intentions are quite different as they both aim at a general characterization of natural kinds. As Slater [2014] puts it: "my account [...] is, I think, an attractive candidate for a general natural kind concept, able to accommodate the diversity of natural kinds we find in the world.” In a similar vein, Franklin-Hall [2014] “argue[s] that natural kinds be identified with 'categorical bottlenecks'.”

Even if my application of Slater's and Franklin-Hall's accounts is fruitful for a discussion of ethnobiology, it can lead to worries about these more traditional philosophical goals. Recall that I 
suggested that domain-relative SPCs are not unique to scientific classification but also ubiquitous in indigenous taxonomies and even in highly specialized forms of LEK that are adapted to unique environments and social contexts. Given that Slater presents SPCs as a general characterization of "natural kindness", my applications may seem to inflate the notion of natural kinds by arguing for SPCs in highly specific LEK-settings. Furthermore, my discussion of domain-transcending SPCs will hardly ease these worries as I have argued that even a bat-bird taxon may be domaintranscending for a range of domains that includes modern biology.

Slater [2014] anticipates metaphysical worries about domain-relativity and suggests that one possible response is to stress "the convergence of different systems of classification on the same categories" and the "robust epistemic role" of categories despite variation of epistemic aims. Clearly, these suggestions match my addition of categorical bottlenecks to the SPC-based model. At the same time, my notion of bottleneck SPCs will provide little comfort to philosophers who look for a metaphysically ambitious notion of natural kinds. Indeed, I have suggested that taxa that are tied to specific LEKs and taxa that do not serve the epistemic aims of scientists do not qualify as bottleneck SPCs. However, they do not qualify because we defined the range of relevant agents in a specific way. For example, we could also use a range of agents that only includes folk-biologists who recognize a bat-bird taxon. Relative to this range, a bat-bird taxon would arguably qualify as a bottleneck SPC. Even some highly specialized LEK-taxa such as tsa' wakax may qualify as bottleneck SPCs if we define a sufficiently narrow range relevant agents such as Tzeltal and other Highland Maya groups in Chiapas such as Tzotzil (cf. Shepard et al. [2008]).

At this point, one may suggest that my account of bottleneck SPCs misses a philosophically crucial aspect of Franklin-Hall's model of categorical bottlenecks. I have assumed that we simple define a range of agents relative to whatever convergence-divergence patterns we're interested in. While I have focused on indigenous and scientific kinds, one may also define the range of agents differently in alternative research projects such as, for example, a comparison of classifications in evolutionary zoology and zoological ecology, Tzeltal and Tzotzil ethnomycology, Pre-Darwinian taxonomies, psychiatric classification manuals, and so on.

In contrast, Franklin-Hall [2014]) does not assume that we simply define the range of agents but instead introduces an "epistemic agent space" that specifies distance between agents in terms of shared epistemic interests and capabilities. The set of relevant agents can be understood as the "set of neighboring agents” that can "itself be understood via an 'epistemic agent space' in which those located near to one another enjoy very similar aims and capacities, while those progressively farther away differ more substantially along either or both of these dimensions. The neighboring agents are those within some threshold of closeness to us. I conjecture that we can grasp the space's structure intuitively." 
Unfortunately, I think that there are two reasons why this epistemic agent space will fail to ease worries of ambitious metaphysicians regarding bottleneck SPCs. First, it is far from clear that this agent space excludes my metaphysically controversial examples such as regional and LEK-specific natural kinds. For example, who are the neighbouring agents of a Tzeltal folk-biologist? First, Tzeltal folk-biologists in neighbouring villages that often use slightly different classifications. Second, Tzotzil folk-biologists who rely on a similar ethnomycological taxonomy (Shepard et al. 2008). Third, other Highland Maya groups. If some LEK-specific taxa are stable for most Highland Maya, however, it is not clear why they should not qualify as natural kinds in the sense of FranklinHall's epistemic agent space. In response one may suggest that a range of Highland Maya agents is too narrow to satisfy Franklin-Hall's requirement of “a wide range of alternative agents.” However, there are also taxa such as my bat-bird taxon that are recognized not only in a regional set of LEKs but globally by various agents with a considerable range of epistemic interests and capabilities.

In addition to these difficulties with supposedly unnatural folk kinds such as a bat-bird taxon, an ambitious natural kind theorist will also remain unsatisfied with the structure of the epistemic agent space. Arguably this is not only because we somehow have to define the required range that is “ultimately relative to us” (Franklin-Hall [2014]) but also because positions in the epistemic agent space are arguably relative to our priorities. Franklin-Hall appeals to an intuitively grasped structure and suggests that we see "immediately that an inquirer aiming only to elucidate patterns in the relative speed of animal locomotion is further from us than one with all of our aims, except disregarding the behavior of wombats.” Sure, but our intuitions in this example clearly derive from the way it is constructed - either we share almost all aims or we share almost no aims with the alternative agents. How do we measure epistemic distance between alternative agents who are not convenient philosophical inventions but share diverse and partly overlapping aims and capabilities? Assuming that we cannot simply quantify over shared epistemic aims, we have to evaluate their relevance in order to determine distance in Franklin-Hall's epistemic agent space. However, it is difficult to see how such an evaluation could work independently for our contingent priorities. This problem becomes even more pressing given that Franklin-Hall assumes that we have to consider both aims and capabilities. How do we weigh shared aims (e.g. of community ecologists and indigenous folk-biologists, cf. Pierotti [2011]) against differences in capabilities? While FranklinHall's idea of an intuitively grasped epistemic agent space may be a useful heuristic, there is little reason to believe that it offers some objective account of epistemic distance between agents.

Does this mean that categorical bottlenecks and SPCs fail to provide a satisfying account of natural kinds? Well, it obviously depends on our expectations regarding the notion of natural kinds. In its most moderate variant, a notion of natural kinds comes with the goal of an "epistemology of classifying natural phenomena” (Love [2008], cf. Brigandt [2011]) instead of metaphysical 
ambitions. Both SPCs and categorical bottlenecks can make useful contributions to our understanding of classification as my discussion of convergence-divergence patterns illustrates. If we limit ourselves to epistemological goals, there is no reason to doubt the importance of both SPCs and categorical bottlenecks. In fact, my discussion suggests that we may actually combine both accounts to specify "three shades of natural kindness”: domain-relative SPCs, domain-transcending SPCs, and bottleneck SPCs.

In addition to these epistemological considerations, the suggested SPC-based model arguably also carries at least some metaphysical weight by providing an alternative to a purely conventionalist model. Clearly, classification in a SPC-based model does not reduce our conventional choices but has to be understood in relation to empirically discovered property clusters. Even domain-relative SPCs of very specific LEKs such as $t s a^{\prime}$ wakax reflect empirically discovered structures of the biological realm in a temporally and spatially restricted environment. If the metaphysical ambition is merely to show that classification of natural phenomena does not reduce to conventions, a SPCbased model arguably provides a helpful framework.

Many traditional accounts of natural kinds, however, clearly aim at much stronger metaphysical goal of identifying a restricted set of genuinely fundamental and interest-independent natural kinds. Both Slater and Franklin-Hall acknowledge that their accounts do not satisfy the demands of this strong natural kind realism. Still, a philosopher with more ambitious metaphysical goals may argue that this only illustrates that SPCs and categorical bottlenecks are not sufficient to capture genuine “natural kindness”. While I share Slater's and Franklin-Hall's skepticism regarding such a metaphysically ambitious natural kind realism, I also assume that the presented SPC-based model is at least logically independent from these metaphysical issues. A SPC-based model provides a helpful framework for thinking about taxonomic convergence-divergence patterns no matter whether we abandon the notion of natural kinds altogether (e.g. Hacking [2007b]; cf. McLeod and Reydon [2013]), interpret the suggested types of SPCs (domain-relative, domain-transcending, and bottleneck) as different "shades of natural kindness", or aim at some more ambitious metaphysics of natural kinds.

Acknowledgements: I would like to thank Roy Ellen, Philip Kitcher, Marcus Ohlström, Shashikala Srinivasan, and the members of the Columbia University Visiting Scholar Workshop for helpful comments on an earlier version of this article.

\section{David Ludwig}

Vrije Universiteit Amsterdam

De Boelelaan 1105 
1081 HV Amsterdam, Netherlands

davidundludwig@gmail.com

\section{References}

Anadón, J. D. et al. [2009]: 'Evaluation of Local Ecological Knowledge as a Method for Collecting Extensive Data on Animal Abundance', Conservation Biology, 23 (3), pp. 617-625.

Atran, S. [1993]: 'Itza Maya Tropical Agro-Forestry', Current Anthropology, 34 (5), pp. 633-700.

—. [1998]: 'Folk Biology and the Anthropology of Science: Cognitive Universals and Cultural Particulars', Behavioral and Brain Sciences, 21 (4), pp. 547-569.

Atran S. and D.L. Medin, [2010]: The Native Mind and the Cultural Construction of Nature. Cambridge: MIT Press.

Bailenson, J. N et al. [2002]: 'A bird's eye view: biological categorization and reasoning within and across cultures', Cognition, 84 (1), pp. 1-53.

Bapteste, E., \& Dupré, J. [2013]: 'Towards a processual microbial ontology', Biology \& Philosophy, 28 (2), pp. 379-404.

Barker, M. J., \& Velasco, J. D. [2013]: 'Deep Conventionalism about Evolutionary Groups', Philosophy of Science, 80 (5), pp. 971-982.

Berlin B., D.E. Breedlove, and P.H. Raven [1973]: 'General principles of classification and nomenclature in folk biology', American Anthropologist 75 (1), 214-242.

Berlin, B., Breedlove, D. E., \& Raven, P. H. [1974]: Principles of Tzeltal plant classification. New York: Academic Press.

Berlin B. [1992]: Ethnobiological classification. Princeton: Princeton University Press.

Boster, JS [1994]: 'The successive pile sort', Field Methods, 6 (2), pp. 11-12.

Boyd, R. [1999]: 'Homeostasis, species, and higher taxa', in R. A. Wilson (ed.), Species: New Interdisciplinary Essays. Cambridge, Mass: MIT Press.

—. [2010]: 'Homeostasis, higher taxa, and monophyly', Philosophy of Science, 77(5), pp. 686-701.

Brakel, J. van [1992]: 'Natural kinds and manifest forms of life', Dialectica, 46(3-4), 243261.

Brigandt, I. [2011]: 'Natural kinds and concepts. A Pragmatist and Methodologically Naturalistic Account ', in J. Knowles and H. Rydenfelt (eds), Pragmatism, Science and Naturalism. New York: Peter Lang, pp. 171-196.

Cardoso, D. B. et al. [2010]: 'Correlations between indigenous Brazilian folk 
classifications of fungi and their systematics', Journal of Ethnobiology, 30 (2), pp. 252264.

Craver, C. [2009]: 'Mechanisms and natural kinds', Philosophical Psychology, 22 (5), pp. 575-594.

De Cruz, H. and Smedt, J.D. [2006]: 'The role of intuitive ontologies in scientific understanding-the case of human evolution', Biology \& Philosophy, 22 (3), pp. 351368.

Davis, A., \& Ruddle, K. [2010]: 'Constructing confidence: rational skepticism and systematic enquiry in local ecological knowledge research', Ecological Applications, 20 (3), pp. 880-894.

Deleuze, G., \& Guattari, F. [1980]: Mille plateaux: Capitalisme et schizophrénie. Paris: Editions de minuit.

Diamond J, [1966]: 'Zoological classification system of a primitive people', Science, 151 (3714), p. 1102.

Dupré, J. [1999]: 'Are whales fish?', in S. Atran and D. Medin (eds), Folkbiology. Cambridge, Mass: MIT Press, pp. 461-476.

Ellen, R.F. [2006]: The categorical impulse. New York: Berghan.

Ereshefsky, M., \& Matthen, M. [2005]: 'Taxonomy, polymorphism, and history: An introduction to population structure theory', Philosophy of Science, 72 (1), pp. 1-21. Ereshefsky, M., \& Reydon, T. A. [2014]: 'Scientific kinds', Philosophical Studies, 1-18. Forth, G. [2010]: 'Symbolic birds and ironic bats', Ethnology , 48 (2), pp. 139-159.

Foucault, M. [2006]: Il faut défendre la société. Paris: Éditions Gallimard.

Franklin-Hall, L. R. [2014]: 'Natural kinds as categorical bottlenecks', Philosophical Studies, advance online publication, pp. 1-24.

Gilchrist, G., Mallory, M., \& Merkel, F. [2005]: 'Can local ecological knowledge contribute to wildlife management?', Ecology and Society, 10(1), p. 20.

Gorelick, R. [2014]: 'Indigenous Sciences are not Pseudosciences', Ideas in Ecology and Evolution, 7, pp. 43-55.

Hacking, I. [2007a]: 'Putnam's theory of natural kinds and their names is not the same as Kripke’s.', Principia, 11(1), pp. 1-24.

—. [2007b]: 'Natural kinds: rosy dawn, scholastic twilight', Royal Institute of Philosophy Supplement, 61, pp. 203-239.

Häggqvist, S. [2005]: 'Kinds, projectibility and explanation', Croatian journal of philosophy, 13, pp. 71-87.

Hunn, E. [1975]: 'A measure of the degree of correspondence of folk to scientific 
biological classification', American Ethnologist, 2(2), pp. 309-327.

-[1982]: 'The utilitarian factor in folk biological classification', American Anthropologist, 84 (4), pp. 830-847.

—. [2007]: 'Ethnobiology in four phases', Journal of Ethnobiology 27 (1), pp. 1-10.

Hunn E.S. and C.H. Brown. [2011]: 'Linguistic ethnobiology', in E.N .Anderson, D.

Pearsall, E. Hunn, and N. Turner (eds), Ethnobiology, Chichester: John Wiley \& Sons, pp. 319-333.

Hunn, E. S., \& Meilleur, B. A. [2010]: 'Commentary on "Indigenous Ecological

Knowledge as Situated Practices', American Anthropologist, 112 (2), pp. 351-351.

Huntington, H. P. [2000]: 'Using traditional ecological knowledge in science', Ecological applications, 10 (5), pp. 1270-1274.

Khalidi, M. A. [2013]: Natural Categories and Human Kinds. Cambridge: Cambridge University Press.

Kitcher, P. [2008]: 'Carnap and the caterpillar', Philosophical Topics, 36 (1), pp. 111-127.

Lampman, A. M. [2004]: Tzeltal ethnomycology. Naming, classification and use of mushrooms in the highlands of Chiapas, Mexico, doctoral dissertation, University of Georgia.

LaPorte, J. [2004]: Natural kinds and conceptual change. Cambridge: Cambridge University Press.

Lévi-Strauss, C. [1962]: La pensée sauvage. Paris: Plon.

Love, A. C. [2009]: 'Typology reconfigured: from the metaphysics of essentialism to the epistemology of representation', Acta Biotheoretica, 57 (1-2), pp. 51-75.

Ludwig, D. [2013]: 'Hysteria, Race, and Phlogiston. A Model of Ontological Elimination in the Human Sciences', Studies in History and Philosophy of Biological and Biomedical Sciences. 45, pp. 68-77.

MacLeod, M., \& Reydon, T. A. [2013]: 'Natural kinds in philosophy and in the life sciences', Biological Theory, 7 (2), pp. 89-99.

Magnus, P. D. [2012]: Scientific enquiry and natural kinds. Palgrave Macmillan.

—. [2014]: 'NK $\neq$ HPC', The Philosophical Quarterly.

Newmaster, S. G. et al. [2007]: 'The multi-mechanistic taxonomy of the Irulas in Tamil Nadu, South India', Journal of Ethnobiology, 27 (2), pp. 233-255.

Newmaster, S. G., \& Ragupathy, S. [2010]: 'Ethnobotany genomics-discovery and innovation in a new era of exploratory research', Journal of Ethnobiology and Ethnomedicine 6 (2).

Nolan JM, [2007]: Wild harvest in the heartland. Lanham: University Press of America

Okasha, S. [2002]: 'Darwinian metaphysics: species and the question of essentialism', 
Synthese, 131 (2), pp. 191-213.

Pierotti R, [2011]: 'The World According to Is’a', in E.N. Anderson et al. (eds), Ethnobiology. Chichester: John Wiley \& Sons.

Ragupathy, S., et el. [2009]: 'DNA barcoding discriminates a new cryptic grass species revealed in an ethnobotany study by the hill tribes of the Western Ghats in southern India', Molecular Ecology Resources, 9 (1), pp. 164-171.

Rieppel, O. [2005]: 'Monophyly, paraphyly, and natural kinds', Biology and Philosophy, 20 (2-3), pp. 465-487.

Sankey, H. [1998]: 'Taxonomic incommensurability', International Studies in the Philosophy of Science, 12(1), pp. 7-16.

Schlesinger, V. [2001]: Animals and plants of the ancient Maya. Austin: University of Texas Press.

Shepard Jr, G. H., Arora, D., \& Lampman, A. [2008]: 'The Grace of the flood: classification and use of wild mushrooms among the highland Maya of Chiapas', Economic Botany, 62(3), pp. 437-470. Sillitoe, P. [2002]: 'Contested knowledge, contingent classification', American Anthropologist, 104 (4), pp. 1162-1171.

Slater, M. H. [2014]: 'Natural kindness', The British Journal for the Philosophy of Science, advance online publication.

Soames, S. [2004]: 'Knowledge of manifest natural kinds', Facta Philosophica, 6, pp. 159-81.

Souza, S. P., \& Begossi, A. [2007]: 'Whales, dolphins or fishes?', Journal of Ethnobiology and Ethnomedicine, 3 (1).

Tobin, E. [2010]: 'Crosscutting natural kinds and the hierarchy thesis', in H. Beebee and SabbartonLeary (eds), The semantics and metaphysics of natural kinds. London: Routledge, pp. 179-191. Watson-Veran, H., \& Turnbull, D. [1994]: 'Science and other indigenous knowledge systems', in Jasanoff et. al (eds), Handbook of Science and Technology Studies. Thousand Oaks: Sage, pp. 115-139.

Wikforss, Å. [2013]: 'Bachelors, energy, cats and water', Theoria, 79(3), pp. 242-261.

Williams, N. E. [2011]: 'Putnam's traditional neo-essentialism', The Philosophical Quarterly, 61(242), pp. 151-170.

Wilson, R. A., Barker, M. J., \& Brigandt, I. [2007]: 'When traditional essentialism fails', Philosophical Topics, 35(1), pp. 189-215.

Winther, R. G. [2011]: 'Part-whole science', Synthese, 178(3), pp. 397-427.

Zent, S. [2009]: 'A genealogy of scientific representations of indigenous knowledge', in S. Heckler (ed.), Landscape, Process, and Power New York : Berghahn Books. 
